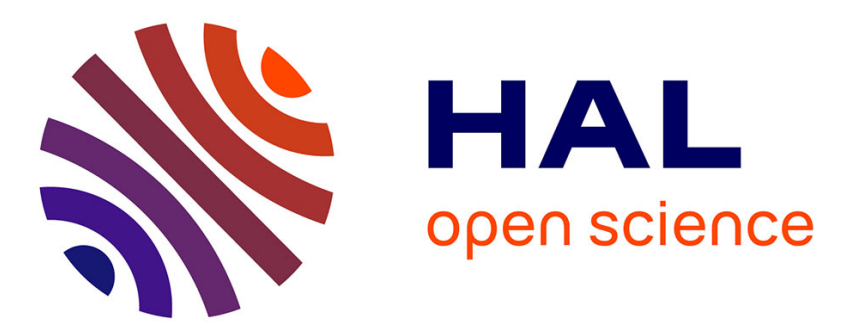

\title{
IPIM Modeling of the Ionospheric F 2 Layer Depletion at High Latitudes During a High-Speed Stream Event
}

A. Marchaudon, P.-L. Blelly, M. Grandin, A. Aikio, A. Kozlovsky, I. Virtanen

\section{To cite this version:}

A. Marchaudon, P.-L. Blelly, M. Grandin, A. Aikio, A. Kozlovsky, et al.. IPIM Modeling of the Ionospheric F 2 Layer Depletion at High Latitudes During a High-Speed Stream Event. Journal of Geophysical Research Space Physics, 2018, 123 (8), pp.7051-7066. 10.1029/2018JA025744 . hal02321970

\section{HAL Id: hal-02321970 \\ https://hal.science/hal-02321970}

Submitted on 21 Oct 2019

HAL is a multi-disciplinary open access archive for the deposit and dissemination of scientific research documents, whether they are published or not. The documents may come from teaching and research institutions in France or abroad, or from public or private research centers.
L'archive ouverte pluridisciplinaire HAL, est destinée au dépôt et à la diffusion de documents scientifiques de niveau recherche, publiés ou non, émanant des établissements d'enseignement et de recherche français ou étrangers, des laboratoires publics ou privés. 


\section{Journal of Geophysical Research: Space Physics}

\section{RESEARCH ARTICLE \\ 10.1029/2018JA025744 \\ IPIM Modeling of the lonospheric $F_{2}$ Layer Depletion at High Latitudes During a High-Speed Stream Event}

Key Points:

- A summertime HSS event is successfully modeled with IPIM when compared with EISCAT and SuperDARN radars, ionosondes, and CHAMP satellite data

- The ionosphere $F_{2}$ region is depleted as atomic oxygen density is reduced due to enhanced polar cap convection and neutral atmosphere heating

- Electrodynamics can explain the short-term depletion of the ionosphere, while long-term effects are due to neutral atmosphere perturbations

Correspondence to:

A. Marchaudon,

aurelie.marchaudon@irap.omp.eu

Citation:

Marchaudon, A., Blelly, P.-L., Grandin, M., Aikio, A., Kozlovsky, A., \& Virtanen, I. (2018). IPIM modeling of the ionospheric $F_{2}$ layer depletion at high latitudes during a high-speed stream event. Space Physics Space Physics, 123. https://doi.org/10.1029/2018JA025744

Received 6 JUN 2018

Accepted 14 JUL 2018

Accepted article online 27 JUL 2018

(C)2018. American Geophysical Union. All Rights Reserved.

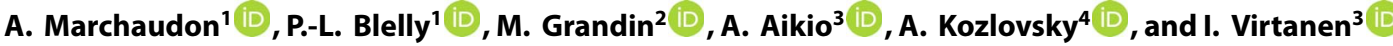 \\ ${ }^{1}$ Institut de Recherche en Astrophysique et Planétologie, Université de Toulouse, CNRS, CNES, Toulouse, France, ${ }^{2}$ \\ Department of Physics, University of Helsinki, Helsinki, Finland, ${ }^{3}$ Ionospheric Physics Research Unit, University of Oulu, \\ Oulu, Finland, ${ }^{4}$ Sodankylä Geophysical Observatory, University of Oulu, Sodankylä, Finland
}

\begin{abstract}
Our aim is to understand the effect of high-speed stream events on the high-latitude ionosphere and more specifically the decrease of the $f_{o} F_{2}$ frequency during the entire day following the impact. First, we have selected one summertime event, for which a large data set was available: Super Dual Auroral Radar Network (SuperDARN) and European Incoherent SCATter (EISCAT) radars, Tromsø and Sodankylä ionosondes, and the CHAllenging Minisatellite Payload (CHAMP) satellite. We modeled with the IPIM model (IRAP Plasmasphere lonosphere Model) the dynamics of the ionosphere at Tromsø and Sodankylä using inputs derived from the data. The simulations nicely match the measurements made by the EISCAT radar and the ionosondes, and we showed that the decrease of $f_{o} F_{2}$ is associated with a transition from $F_{2}$ to $F_{1}$ layer resulting from a decrease of neutral atomic oxygen concentration. Modeling showed that electrodynamics can explain short-term behavior on the scale of a few hours, but long-term behavior on the scale of a few days results from the perturbation induced in the atmosphere. Enhancement of convection is responsible for a sharp increase of the ion temperature by Joule heating, leading through chemistry to an immediate reduction of the $F_{2}$ layer. Then, ion drag on neutrals is responsible for a rapid heating and expansion of the thermosphere. This expansion affects atomic oxygen through nonthermal upward flow, which results in a decrease of its concentration and amplifies the decrease of $[\mathrm{O}] /\left[\mathrm{N}_{2}\right]$ ratio. This thermospheric change explains long-term extinction of the $F_{2}$ layer.
\end{abstract}

\section{Introduction}

Solar wind high-speed streams (HSSs) are the most important source of geomagnetic disturbances during the declining phase of the solar cycle (Tsurutani et al., 2006). Despite several studies carried out during recent years, the global ionospheric response to HSSs is neither fully documented nor understood yet.

The HSSs are created by the fast flow of solar wind plasma along open solar magnetic field lines, which originate from the coronal holes. During the declining phase of the solar cycle, coronal holes from the polar regions tend to migrate to lower heliographical latitudes, and the resulting HSSs of solar wind may reach the ecliptic plane. When the fast solar wind (velocity $>500 \mathrm{~km} / \mathrm{s}$ ) catches up to the slower wind, this creates a compression region characterized by strong interplanetary magnetic field (IMF) magnitude, high solar wind density, and high pressure, called corotating interaction regions (CIR ; Gosling, 1996). Such structures often show a 27-day recurrence, corresponding to the solar rotation period near the equator, which implies that a same coronal hole may persist for several solar rotations. It has been estimated that the CIRs and following HSSs are more geoeffective than coronal mass ejections, (CMEs) even though the energy input into the planetary environments by HSS events is generally smaller than for CMEs (Turner et al., 2009).

The HSS effects on the global ionosphere-thermosphere system have been studied in several papers. In particular, there is evidence of heating of the thermosphere in response to CIRs and HSSs. Increased geomagnetic activity results in a global increase in the neutral density at a fixed altitude of $340 \mathrm{~km}$, as was observed by Thayer et al. (2008) using the measurements of the CHAllenging Minisatellite Payload (CHAMP) satellite. Using column density ratio $\Sigma \mathrm{O} / \mathrm{N}_{2}$ measured with the Global UltraViolet Imager (GUVI) instrument onboard the Thermosphere lonosphere Mesosphere Energetics and Dynamics (TIMED) satellite (Strickland et al., 1995). Crowley et al. (2008) also showed neutral composition changes in response to successive HSSs. These composition variations were observed all over the world, with moderate increase in the $\Sigma \mathrm{O} / \mathrm{N}_{2}$ ratio at midlatitudes and strong depletion at high latitudes, reaching $15 \%$ deviation. 
Sojka et al. (2009) studied the effect of CIRs on the high latitude and polar ionospheres by using two incoherent scatter radar facilities during the International Polar Year. The auroral zone Poker Flat Incoherent Scatter Radar (PFISR) showed an increase in the median value of the ion temperature $\left(T_{i}\right)$ from roughly 850 to $950 \mathrm{~K}$ during 1 day and a slow decay over 4 days. The polar cap station European Incoherent SCATter (EISCAT) Svalbard Radar showed a similar general behavior. In addition to slow variations, the data had many short-lived peaks plausibly associated with localized substorm activity. The variations in the magnetic local time (MLT) or seasonal variations were not considered.

During solar minimum, Heelis and Sojka (2011) also found that HSS may induce polar cap potential increase from 20 to $60 \mathrm{kV}$, causing a neutral temperature increase in the auroral zones and the polar cap over a few hours. This neutral heating was attributed to increase in the frictional heating, and the ionosphere response was found to be asymmetric, with mainly an ion temperature increase from 100 to $150 \mathrm{~K}$ in the morningside and an $\mathrm{O}^{+}$concentration increase in the afternoonside. Using qualitative simulations from the Utah State University (USU) global thermosphere model, Gardner et al. (2012) confirmed the thermospheric heating up to $100-150 \mathrm{~K}$, caused by the HSS passage. It starts with the cross polar cap potential increase and continues throughout the period of high potential. Cooling occurs when the cross polar cap potential starts to decrease and takes several days to return to background neutral temperature, in agreement with Sojka et al. (2009).

In Grandin et al. (2015), a phase-locked superposed epoch analysis was carried out to study the effects of HSSs on the high-latitude ionosphere, using data from the Sodankylä ionosonde $(L=5.25)$ during 3 years of the late declining phase of cycle 23 . Zero epoch represented the time when the solar wind speed started to increase, and the maximum velocity was reached during days $D_{1}-D_{2}$. It was found that the $F$ layer critical frequency $f_{o} F_{2}$ decreased in the afternoon sector in winter, in the whole noon-to-midnight sector during equinoxes, and at most MLTs in summer. This effect was strongest on day $D_{2}$ in summer but lasted several days from day $D_{2}$ to at least day $D_{4}$ in equinox and winter. The strongest depletions occurred during equinoxes. This effect was also observed on the midlatitude ionosphere by Denton et al. (2009), whose main conclusion was that on average HSSs cause a sharp decrease in the $f_{o} F_{2}$, which begins at the onset of magnetospheric convection. A period of more than 4 days was required for the ionosphere to return to pre-event levels. The decrease was found to be consistent with the onset of the $F$ region ionospheric storm at midlatitudes.

It was suggested by Grandin et al. (2015) that increased ionospheric electric fields could be behind the observation. Those produce ion-neutral frictional heating in the auroral and subauroral regions. The frictional heating can increase the loss rate of $\mathrm{O}^{+}$ions due to two reasons. The first one is neutral heating producing thermal expansion of the atmosphere and enhancing $\mathrm{N}_{2}$ and $\mathrm{O}_{2}$ at the $F$ region peak. The second one is ion heating, leading to enhancement of the reaction coefficients. In addition to the pronounced $F$ region peak electron density decrease, an increase in $f_{o} F_{2}$ was observed in two different MLT sectors. First, a short-lived increase was visible near noon on the first day after the arrival of the HSS during all seasons, possibly triggered by the CIR solar wind pressure pulse, which may produce particle precipitation from the dayside central plasma sheet. Second, $f_{o} F_{2}$ was enhanced for several days in the postmidnight and morning sectors during equinoxes and in winter, while in summer this effect was not visible, perhaps due to larger background $F$ region electron densities. It was suggested that this was caused by low-energy particle precipitation. Also, $E$ region densities were increased within the same sector, during all seasons, indicating coexisting auroral- and low-energy precipitation.

The study by Grandin et al. (2015) was extended in Grandin et al. (2017) to investigate the energetic (> $30 \mathrm{keV}$ ) particle precipitation at auroral and subauroral latitudes $(L=3.8-5.7)$ by using cosmic noise absorption (CNA) data measured by the Finnish riometer chain during the HSS events. CNA was observed to last at least for 3 days after the CIR arrival at the bow shock. CNA was divided into three categories, depending on whether it was associated with local substorm activity, with ultralow frequency (ULF) wave activity, or neither of these. Substorm-type CNA dominated in the 21-06 MLT sector, while ULF-type CNA dominated from morning to afternoon.

Based on the statistical results and discussion in Grandin et al. (2015), we are specifically interested in investigating the following features: (1) The decrease of $F$ region peak density during high values of solar wind speed; (2) possible enhancement in electric field values on the flux tubes, where $F$ peak decrease exists and associated enhanced ion and/or neutral temperature; and (3) possible effects of vertical transport of $\mathrm{O}^{+}$ions away from the peak density altitude. In this paper, we have chosen to study in detail one HSS event, through 


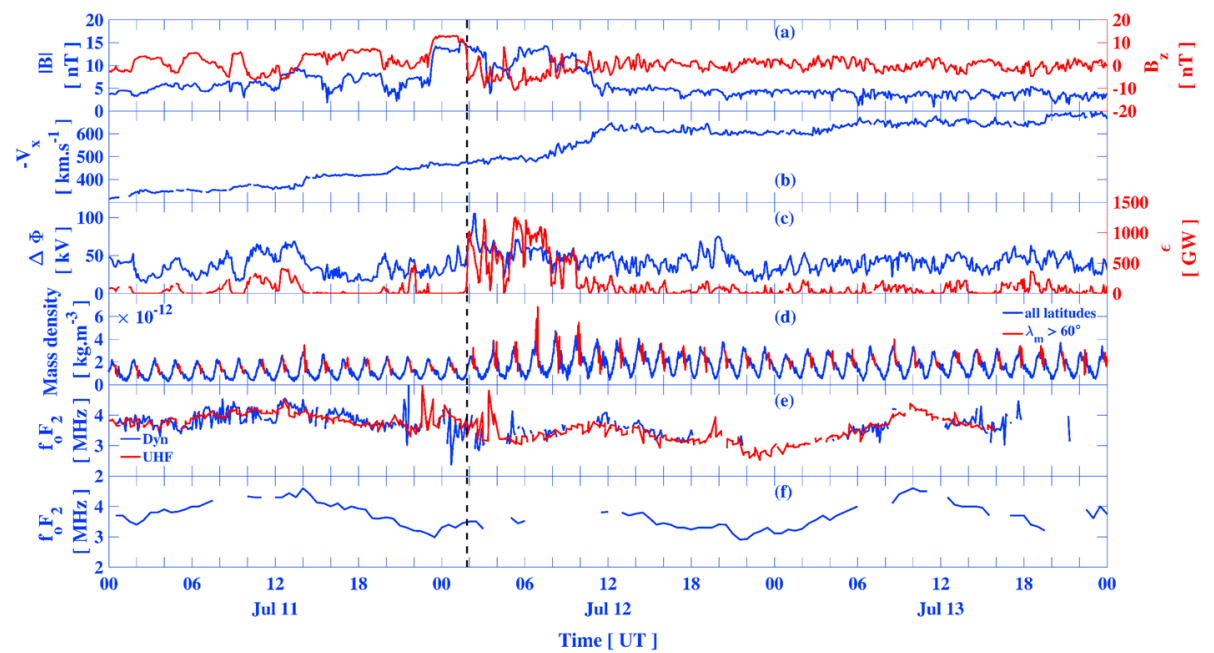

Figure 1. Dynamics of the magnetosphere-ionosphere-thermosphere system during the period encompassing the HSS event for 11-13 July 2008. Panel (a) represents the temporal evolution of the IMF magnitude (blue) and of the $B_{z}$ component (red) in Geocentric Solar Magnetospheric (GSM) coordinates. Panel (b) shows the solar wind velocity $-V_{x}$ component, along the Sun-Earth axis. Panel (c) shows the cross polar cap potential derived from SuperDARN convection maps (blue) and the solar wind-magnetosphere energy coupling function Akasofu epsilon (red). Panel (d) represents the temporal evolution of the mass density derived from CHAMP accelerometer measurements at all latitudes (blue) and above $60^{\circ}$ MLAT only (red). Panel (e) gathers the $f_{o} F_{2}$ frequency at Tromsø location measured by EISCAT UHF radar and by the dynasonde. Panel (f) shows the $f_{o} F_{2}$ frequency as measured by the ionosonde at Sodankylä. The black dashed vertical line around 02:00 UT (on day 12) indicates the southward IMF turning and the enhancement of the magnetosphere-ionosphere coupling.

ionospheric modeling and comparison with observations. After presenting the context of the event and the different data sets used in section (2), we will shortly describe the IRAP Plasmasphere lonosphere Model (IPIM) and the way inputs of the model have been optimized in section (3) followed by a description of the results in section (4), discussion in section (5) and conclusion in section 6.

\section{Context and Observations}

The aim of this paper is to use modeling to study the impact of one HSS event on the high-latitude ionosphere. In order to check the modeling validity, we need data sets used as a reference. For this purpose, we searched for several daylong ionospheric high-latitude observations by the EISCAT radars, including an electric field measurement. This kind of experiment was not easy to find, because the conditions for search were as follows: (i) measurements at least 1 day before the CIR interface hits the bow shock and several days afterward and (ii) electric field estimates at Tromsø which requires either operation of all the three EISCAT receivers at Tromsø, Kiruna, and Sodankylä (tri-static observation) or alternatively the antenna scan pattern of the Tromsø radar (CP-2 mode).

The chosen event occurred during the beginning of the peculiar minimum of Solar Cycle 24 close to summer solstice in the Northern Hemisphere (NH) from 11-13 July 2008. This event has been chosen because the $F_{2}$ region depletion is clearly observed in the ionosphere during only 1 day as is typical for summer conditions and because of the large number of available data sets which are used either for comparison with the modeled results or as inputs for the IPIM model. By chance, this event has also been studied by Heelis and Sojka (2011) and Gardner et al. (2012) and comparison between their results and ours will help strengthen our interpretation. Below are listed the different facilities whose data have been extensively used.

The Tromsø EISCAT radar was in operation from 00:00 UT 10 July to 15:00 UT 13 July, in a meridional scanning mode with a full scan of 12 directions obtained in about $24 \mathrm{~min}$ ( $2 \mathrm{~min}$ per position). Through incoherent scatter of radio waves by the ionospheric plasma, the radar is able to retrieve altitude profiles of important ionospheric parameters such as the electron density, the electron and ion temperatures, and the line-of-sight velocity. Moreover, tristatic measurements between Troms $\varnothing\left(\lambda_{\mathrm{CGM}}=66.73^{\circ}, \mathrm{MLT}=\mathrm{UT}+2.5\right)$, Sodankylä $\left(\lambda_{\mathrm{CGM}}=64.14^{\circ}, \mathrm{MLT} \approx \mathrm{UT}+2.5\right)$, and Kiruna $\left(\lambda_{\mathrm{CGM}}=64.89^{\circ}\right)$ allow retrieval of the convection electric field in their common scattering volume for each pointing beam direction. For this event, we concentrate on altitude 
profiles of plasma parameters and convection electric field obtained from the vertical and field-aligned directions only. Detailed data analysis was also performed to retrieve the exospheric temperature.

Eleven of the Northern Hemisphere Super Dual Auroral Radar Network (SuperDARN) coherent high-frequency (HF) radars were in operation during this period, with scanning modes allowing retrieval of line-of-sight velocity of the ionospheric plasma along 16 beams ( $~ 53^{\circ}$ azimuth) in 1- to 2-min resolution (Greenwald et al., 1995). Combining the data of all the radars allowed obtaining global convection maps (Ruohoniemi \& Baker, 1998) and extracting the Polar Cap Potential (PCP) as the potential difference between the two opposite convection cells on each side of the noon-midnight meridian.

lonosondes at Sodankylä and at Troms $\varnothing$ were also available throughout the period of interest, giving access to $E$ layer and $F_{2}$ layer critical frequencies $\left(f_{o} E\right.$ and $\left.f_{o} F_{2}\right)$ with 30-min resolution.

Finally, the CHAMP satellite was also used to retrieve total mass densities inferred from the accelerometer instrument, at the satellite altitude near $340 \mathrm{~km}$.

Solar wind conditions as seen at the Earth's bow shock with Operating Missions as a Node on the Internet (OMNI) display all the signatures of a HSS event and are characterized in particular by a smooth and long-lasting increase of the solar wind speed from less than $350 \mathrm{~km} / \mathrm{s}$ at 00:00 UT (day 11) up to almost $700 \mathrm{~km} / \mathrm{s}$ at 23:00 UT (day 13; see Figure 1b). Using the method described in Grandin et al. (2017), the zero epoch (start) of this event would be at 12:00 UT on day 11, but the velocity maximum is reached at 12:00 UT on day 12. Strong increases of the IMF magnitude (see Figure 1a) and of the total pressure (not shown) are also observed halfway through the speed ramp, starting around 23:00 UT (day 11), lasting until 12:00 UT (day 12) and reaching more than $10 \mathrm{nT}$ and $100 \mathrm{pPa}$. Concomitant with the IMF magnitude increase, a strong southward IMF turning (see black dashed vertical line in Figure 1a) is also observed from 02:00 UT to 10:00 UT (day 12) causing an intensification of the solar wind-magnetosphere coupling.

This brief and strong coupling reinforcement is evident on several data sets usually used to evaluate this coupling: solar wind coupling functions, magnetic indices, and polar cap potential. The $D_{s t}$ index (not shown) (Sugiura, 1964) exhibits the signature of a moderate magnetic storm reaching its minimum value of about $-40 \mathrm{nT}$ around 08:00 UT on day 12. It remains lower $(\sim-20 \mathrm{nT})$ than its zero-level until the end of day 13. The solar wind-magnetosphere energy coupling function Akasofu epsilon (Akasofu, 1979) shows weak increases during day 11, especially around 11-14 UT when the beginning of the HSS is identified and then clearly displays a strong increase when the IMF turns southward and stays elevated until the IMF magnitude decreases and the IMFB $B_{z}$ starts oscillating around 0 (see red line in Figure 1c). When the IMF turns southward, the SuperDARN PCP also shows a strong and brief peak reaching almost $100 \mathrm{kV}$, followed by a moderate value around $50 \mathrm{kV}$ up to 21:00 UT (day 12), confirming a persistent activity in the magnetosphere-ionosphere system during the HSS event (see blue line in Figure 1c). Before and after this period, the PCP is globally lower and shows more variability.

The thermosphere also shows strong modification after the southward IMF turning, since thermospheric density plotted along the CHAMP satellite's orbit displays a rapid increase at all latitudes (blue curve in Figure 1d), and even more at Northern Hemisphere high latitudes (superimposed red curves in Figure 1d). As for the $D_{s t}$ index, the density remains higher after than before the event until the end of day 13.

Looking at the Sodankylä ionosonde data (Figure 1e) and at the Tromsø EISCAT radar and dynasonde data (Figure 1f), the natural diurnal variation of $f_{o} F_{2}$ is observed during the 3 days of interest (day 11 to day 13), with increase during daytime and decrease during nighttime. However during day 12 , the $f_{o} F_{2}$ frequency is lower than during the previous (day 11) and following (day 13) days. As already stated before, this depleted $F_{2}$ region is the effect which we seek to model in this paper.

\section{Modeling of the Event 3.1. IPIM Model}

The IPIM model (Marchaudon \& Blelly, 2015) is a legacy of TRANSCAR ionospheric family models (Blelly et al., 1996, 2005). This model has been developed mainly for interhemispheric studies. As such, it describes the transport equations of ionospheric plasma species along magnetic closed field lines. For this study, we have adapted IPIM to high latitudes open field lines using TRANSCAR approach. Thus, the model solves the transport equations of six ions $\left(\mathrm{H}^{+}, \mathrm{O}^{+}, \mathrm{N}^{+}, \mathrm{N}_{2}^{+}, \mathrm{NO}^{+}\right.$, and $\left.\mathrm{O}_{2}^{+}\right)$and thermal electrons along open field lines, in an eccentric dipole-tilted configuration, with a 13-moment approach. The corresponding equations are 


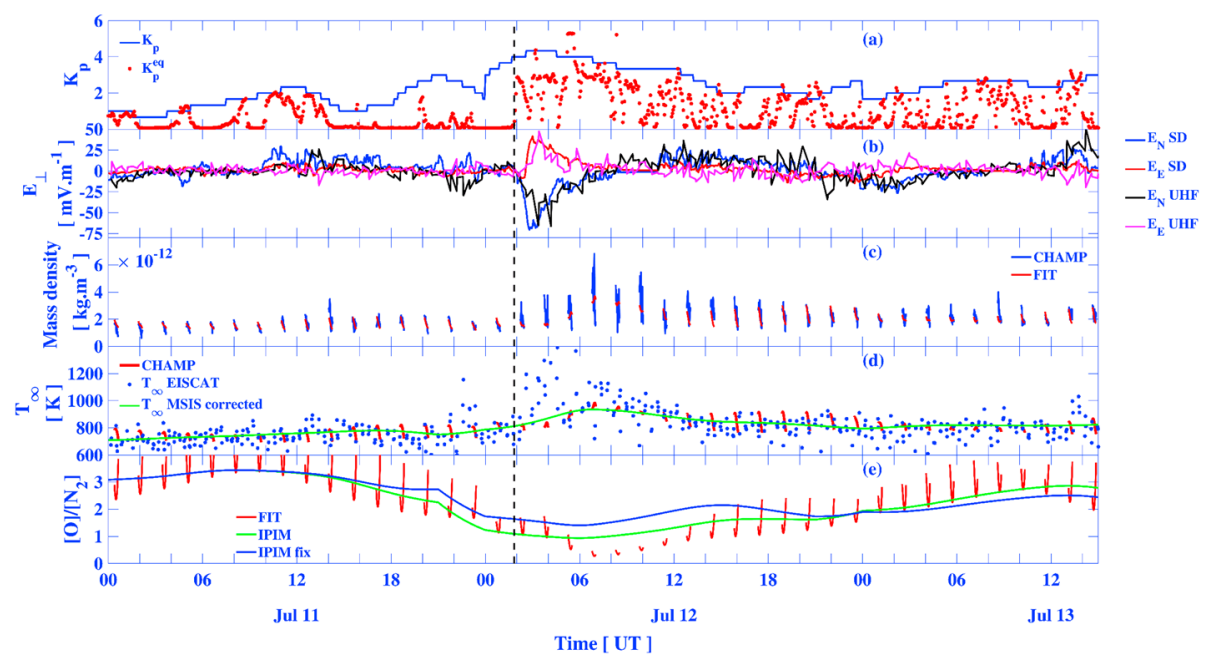

Figure 2. Input parameters. Panel (a) represents equivalent $K_{p}^{\text {eq }}$ parameter (red dots) built from OVATION-Prime maps along with historical $K_{p}$ index (blue). Panel (b) shows the temporal evolution of the eastward $\left(E_{E}\right)$ and northward $\left(E_{N}\right)$ component of the electric field at Tromsø location from SuperDARN (SD) and from EISCAT (UHF). Panel (c) shows the CHAMP accelerometer mass density measurements at $340 \mathrm{~km}$ above $60^{\circ}$ MLAT (blue) along with the mass density estimated from NRLMSISE-00 model (red). Panel (d) presents the corrected exospheric temperatures used in NRLMSISE-00 along CHAMP path (red) and for Tromsø IPIM simulations (green). The temperature inferred from EISCAT is also plotted (blue dots). Panel (e) shows the $[\mathrm{O}] /\left[\mathrm{N}_{2}\right]$ ratio correction applied to NRLMSISE-00 along CHAMP path (red) and the ones used in IPIM (green) and IPIM-fix (blue) simulations. The black dashed vertical line is the same as in Figure 1.

described in Blelly and Schunk (1993). The fluid module is coupled to a kinetic module which solves the Boltzmann transport equation of suprathermal electrons along the field lines: the fluid part provides the thermal electron density and temperature to the kinetic part which in return provides the ion production and thermal electron heating rates.

\subsection{Inputs}

\subsubsection{Solar Flux}

We use the Flare Irradiance Spectral Model (FISM, Chamberlin et al., 2007) to model the solar flux. This model is based on the TIMED and Upper Atmosphere Research Satellite (UARS) satellites measurements and is provided between 0.1 and $190 \mathrm{~nm}$ with a resolution of $1 \mathrm{~nm}$ for every day. Comparison has been made with TIMED measurements for the 3 days, and the model was shown to be representative of the true solar flux all over the period.

\subsubsection{Precipitation}

A run of the empirical OVATION-Prime model (Newell et al., 2009; Sotirelis \& Newell, 2000) was requested at the Community Coordinated Modeling Center (CCMC). Unfortunately, despite a good temporal resolution, the OVATION-Prime model only gives access to maps of total integrated energy flux of electrons, while IPIM requires integral energy and number flux of precipitating electrons. Nevertheless, the OVATION-Prime maps show very consistent spatial pattern with the historical electron precipitation model developed by Hardy et al. (1987). This last model is parametrized by the 3-hr $K_{p}$ index (Bartels, 1949) and thus suffers from a very poor temporal resolution as well as a succinct resolution with magnetic activity with only seven different levels available. To overcome this problem, a modified version of the Hardy's model has been used as input for IPIM where an equivalent $K_{p}^{\text {eq }}$ parameter was built from OVATION-Prime maps and fed into Hardy's model (see red dots in Figure 2a). The methodology to retrieve this equivalent $K_{p}^{\mathrm{eq}}$ parameter is described in Appendix A. With this equivalent $K_{p}^{\text {eq }}$, Hardy's model is able to follow rapid activity variations while smoothing the global precipitation pattern. Though not perfect, this approach gives a proper description of the precipitation dynamics compared to the standard $K_{p}$ index (see blue line in Figure 2a). In particular, the perturbation at 02:00 UT on day 12 (black dashed vertical line) is smeared out by $K_{p}$ index while it is clearly modeled by $K_{p}^{\mathrm{eq}}$.

\subsubsection{Convection}

SuperDARN global convection maps are used as input to IPIM for convecting plasma tubes. Data from all SuperDARN Northern Hemisphere radars are first gathered on a common grid and are then fitted over a statistical convection model driven by the IMF conditions to give global maps. For this particular use, maps are 
averaged over $5 \mathrm{~min}$ in order to smooth out rapid variations. These maps show strong convection intensification around 02:00 UT (day 12) in association with the southward IMF turning. This intensification lasts only a few hours, and convection data become sparse around 04:00-05:00 UT. Comparing global convection maps with local convective electric field measured by the EISCAT, Troms $\varnothing$ radar shows despite different measurement techniques very satisfactory results apart during the strong convection event centered on 03:00 UT (see Figure 2b). The 5-min smoothing of the SuperDARN global convection maps could partly explain this discrepancy. To overcome it, a convection spot has been artificially added to the SuperDARN global convection maps centered on $75^{\circ} \mathrm{MLAT}$ and $4.5 \mathrm{MLT}$ with a rapid increase phase just before the maximum of convection at 03:00 UT, followed by a slower decrease phase with a complete fading around 07:00 UT. With this supplementary spot, SuperDARN convection almost perfectly matches EISCAT-Troms $\varnothing$ convection as is evident in Figure $2 \mathrm{~b}$ where SuperDARN and EISCAT-Tromsø northward and eastward convection electric field components are plotted.

\subsubsection{Atmosphere}

IPIM uses Naval Research Laboratory Mass Spectrometer Incoherent Scatter radar (NRLMSISE-00; Picone et al., 2002) as atmosphere model. However, this empirical model is a climatological model which requires some calibration for any given date and though the dependency on the $a_{p}$ index (equivalent to $K_{p}$ index in true units) gives a basic line for perturbation of magnetospheric origin, some supplementary specific corrections may be necessary. As a result, the NRLMSISE-00 model has been adapted so that the temperature profile can be parameterized by an exospheric temperature $T_{\infty}$ provided externally and the different neutral species concentration profiles can be adjusted by some correction coefficients (one for atomic oxygen $\mathrm{O}$ and one for molecular species $\mathrm{N}_{2}$ and $\mathrm{O}_{2}$; Blelly et al., 1996).

Figure 2c presents the temporal evolution of mass density at the altitude of CHAMP satellite (around $340 \mathrm{~km}$ ) above $60^{\circ}$ MLAT (blue lines). Then, we used NRLMSISE-00 to derive the equivalent mass density along the track of the satellite (red lines). The results were such that on day 11, the model density was higher than the measured one by a factor of about 2. So we modeled EISCAT measurements on the whole day 11 using IPIM and adjusted consistently NRLMSISE-00 parameters to derive the following correction coefficients on composition: 0.6 for atomic oxygen and 1.2 for molecular neutrals. Using TIMED/GUVI measurements, Meier et al. (2015) have shown that the NRLMSISE-00 model generally overestimates $\mathrm{O}$ and $\mathrm{N}_{2}$. In particular, close to the solar minimum of 2008 , they found that NRLMSISE-00 model should be corrected by a factor of about 0.65 around $340 \mathrm{~km}$, which is in agreement with our estimate.

Then, we used these coefficients in NRLMSISE-00 for deriving the neutral temperature from CHAMP data. For that, we assumed that the density variation was mainly driven by a change in the neutral temperature profile, as a result of heating by the electrodynamics. The temperature derived from CHAMP orbital data above $60^{\circ} \mathrm{MLAT}$ is shown as red curves in Figure $2 \mathrm{~d}$, and the green curve represents the corresponding exospheric temperature that is used to correct NRLMSISE-00 densities. We have added with blue dots the exospheric temperature that we derived from the EISCAT data using the technique presented in Blelly et al. (2010). The estimation of the latter suffers from noisy data, but nevertheless, there is a good comparison between both approaches. In particular, the perturbation is well reproduced, even if the EISCAT analysis gives a much larger variation of the exospheric temperature during the maximum of the perturbation.

For the simulation, two sets of composition coefficients have been used. One set of fixed coefficients corresponds to the adjustment on day 11 (hereafter referenced as IPIM-fix). However, these parameters do not allow a proper modeling of the perturbation and we used another set of coefficients (hereafter referenced as IPIM) which are the same as the first set outside the perturbation but vary during the perturbation: oxygen coefficient is decreased from 0.6 to 0.35 and molecular coefficient is decreased from 1.2 to 1 . After the perturbation, the molecular coefficient is kept constant at 1 while oxygen is increased up to 0.6. Figure 2e represents the result on [O]/[ $\left.\mathrm{N}_{2}\right]$ ratio at $340 \mathrm{~km}$ along CHAMP (red) and at Tromsø location for IPIM (green) and IPIM-fix (blue) simulations. The difference between the last two curves is mainly due to the change in the concentration of atomic oxygen which is reduced by almost a factor of 2 during the event.

As far as the neutral wind is concerned, we used the HWM14 wind model which is the updated version of the Horizontal Wind Model 2007 version (HWM07, Drob et al., 2008; Emmert et al., 2008). This model provides a quiet thermospheric wind on which a disturbed component is superimposed. The model provides the horizontal wind (meridional and zonal components) but has no vertical component. Thus, the field-aligned component of the wind results only from the projection of the wind along the magnetic field. We are aware 

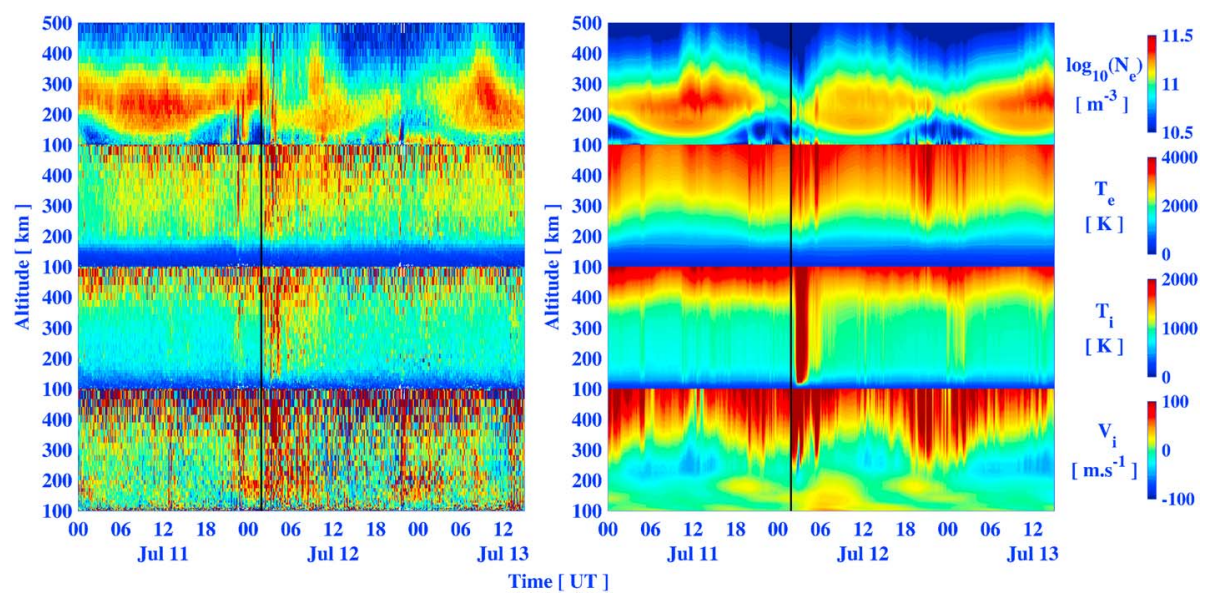

Figure 3. Temporal evolution of field-aligned profiles of from top to bottom: electron density, electron temperature, ion temperature, and ion velocity from Tromsø EISCAT-UHF radar data (left panel) and from IPIM simulation at Troms $\varnothing$ location (right panel). EISCAT parameters are issued from standard GUISDAP analysis and corrected using Blelly et al. (2010) analysis. The calibration constant for density has been changed according to Tromsø ionosonde measurements. IPIM simulation uses the optimized inputs for the HSS event including the variable atmospheric parameter set. The black vertical line corresponds to the dashed one in Figure 1.

that any heating of the atmosphere will first result in an expansion of the atmosphere with a strong transient vertical wind which may exceed $100 \mathrm{~m} / \mathrm{s}$ (Innis et al., 1999). This transient regime cannot be parameterized by the atmospheric model as we do not account for any dynamics nor for any change in the wind structure. So, in order to account for this effect, we have added a perturbation on the field-aligned component of the wind which follows the temperature evolution.

\section{Results}

We ran the model with the inputs described in section 3.2 with the two sets of correction coefficients for NRLMSISE-00, and we present in this section the results obtained from simulations at Troms $\varnothing$ and Sodankylä locations. Troms $\varnothing$ can be considered as the reference test, since we can compare to the full profiles measured by EISCAT-UHF radar, and we consider Sodankylä as the blind test. The runs last from 00:00 UT on 11 July 2008 to 15:00 UT on 13 July 2008 to match the EISCAT observations which also stop at 15:00 UT (day 13). In the following, all the figures displaying temporal evolution will show this time interval.

Figure 3 presents a global view of the measurements obtained with the EISCAT-UHF radar (left panel) and the simulation made with IPIM model (right panel). This is a classical representation where we plot profiles of, from top to bottom, electron density, electron temperature, ion temperature, and ion velocity in a 2-D color coded fashion, with the time running horizontally and the altitude vertically. To ease the comparison, we have used the same color scales for the measurements and the simulation, which are given in the color bar on the right of the figure. Concerning the measurements, as EISCAT was running in a scan mode, we only kept the vertical and field-aligned measurements in order to be compatible with the simulation, as the code solves the field-aligned transport of the ionospheric plasma.

First of all, we clearly see on the measurement density panel the diurnal evolution for the three consecutive days encompassing the perturbation. As the event took place in July, the ionosphere is always illuminated with a solar zenith angle varying between $47^{\circ}$ and $88^{\circ}$, and we can follow the evolution of the $F_{1}$ region, which is almost the same from one day to the other. The simulation on the right panel presents the same structure with a bottom line moving from about $200 \mathrm{~km}$ around midnight to approximately $130 \mathrm{~km}$ around noon. Concerning the $F_{2}$ region, we can see that there is a different behavior from day to day. On day 11 , the measurements show a well-developed $F_{2}$ region which is maintained throughout the day, between 200 and $300 \mathrm{~km}$. This layer disappears on day 12 and starts recovering on day 13 . Some structures appear in the day sector (around 10:00 UT, 12:30 MLT) above $300 \mathrm{~km}$ on both days 12 and 13, which are not visible on day 11 . With the input parameters adjusted for Troms $\varnothing$, the simulation reproduces quite well this day to day evolution with the same amplitude, but we are not able to reproduce these high-altitude structures on days 12 and 13 . 

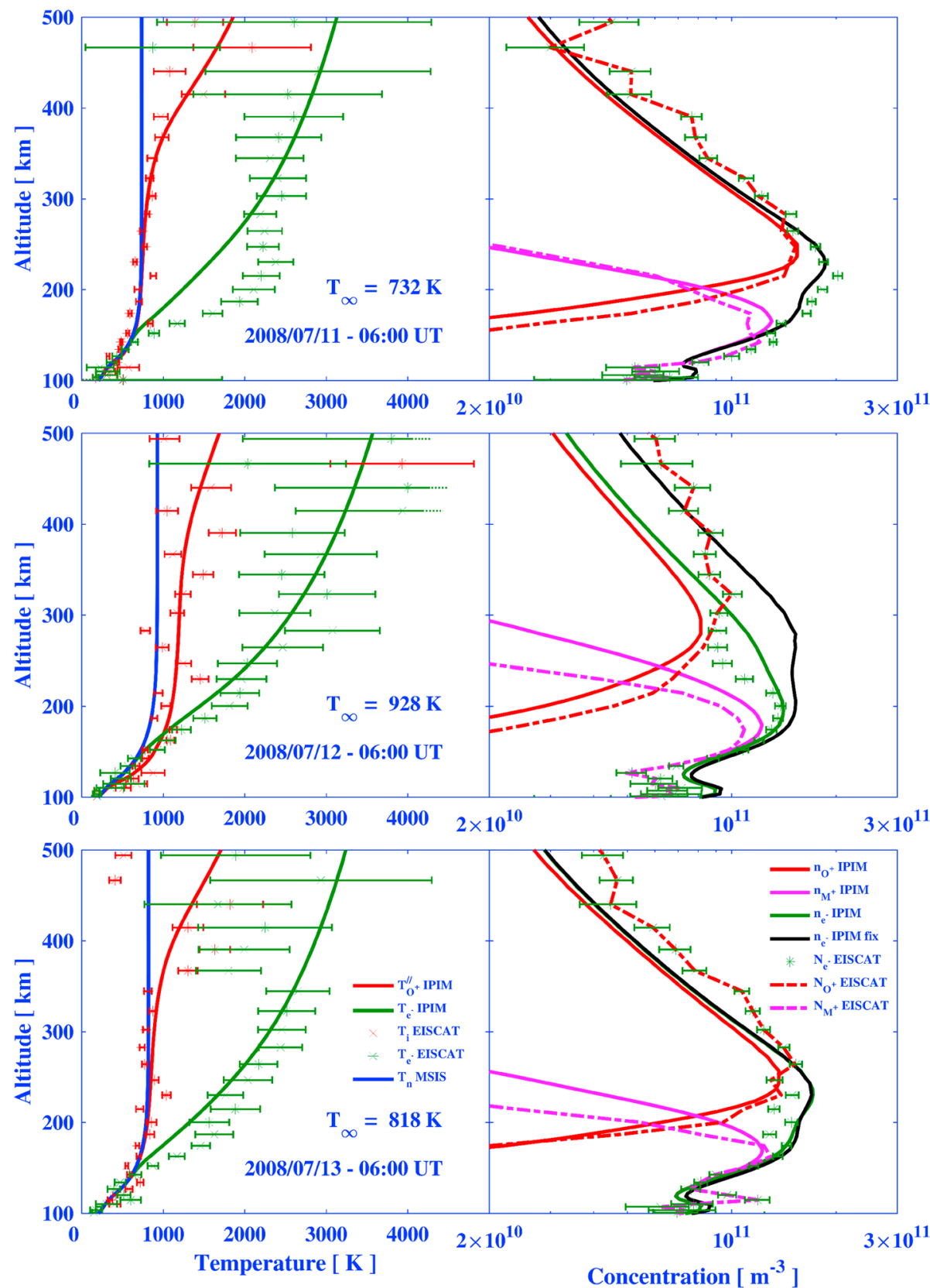

Figure 4. Comparison between EISCAT and IPIM vertical profiles of temperature (left column) and density (right column) between 100 and $500 \mathrm{~km}$ altitude, for the different ionospheric species. The profiles are plotted at 06:00 UT on 11 July 2008, the day before the perturbation (top row); on 12 July 2008, a few hours after the perturbation impact (middle row); and on 13 July 2008, the recovery day after the main impact (bottom row). Left column shows electron (green) and ion (red) temperatures from EISCAT data (stars with corresponding errors bars) and from IPIM simulation with variable atmospheric parameter set (solid lines). NRLMSISE-00 neutral temperature (blue), as used in the simulation and resulting from the analysis of CHAMP data, is also plotted ( $T_{\infty}$ value is indicated in each panel). Right column shows electron (green), atomic $\mathrm{O}^{+}$ion (red), and molecular $\left(\mathrm{M}^{+}\right)$ion (magenta) density obtained from IPIM simulation with variable atmospheric parameter set (solid lines). The electron density from EISCAT (green stars with error bars) and the ion composition structure derived from the EISCAT data analysis from Blelly et al., 2010 (dashed lines and same color code as IPIM) are also plotted. The electron density obtained through the IPIM simulation with fixed atmospheric parameter set has been added for comparison (black solid line). 
If we look at the $E$ region, which is very sensitive to the precipitation, we see that the model is not so good to reproduce the auroral structures, though the time of occurrence is correctly modeled.

A first perturbation caused by the strong increase of the IMF magnitude (see Figure 1a) and of the total solar wind pressure (not shown) at 23:00 UT on day 11 is clearly visible on all EISCAT panels, but is not reproduced by the simulation. The next perturbation, starting at 02:00 UT on day 12 and associated with the southward IMF turning (black dashed vertical line), can be seen as the onset of the response of the atmosphere-ionosphere system to the perturbation, since the ionosphere is deeply altered afterward. This perturbation is characterized by a strong enhancement of all parameters and is followed by a significant modification of the density structure. In parallel to this change, a strong upward ion velocity period starts (red velocities) and is maintained for at least $6 \mathrm{hr}$ with velocities as high as $100 \mathrm{~m} / \mathrm{s}$ in the lower ionosphere. The main features of this event are well reproduced by the simulation.

Beside the aforementioned global behavior, we have also looked at the vertical structure of the ionosphere. With regard to this, we focused on three profiles corresponding to the same time on the three consecutive days. We have chosen 06:00 UT because it is a period just after the perturbation on day 12 and before the two structures observed in $F_{2}$ region on days 12 and 13 .

Figure 4 presents, from top to bottom, profiles between 100 and $500 \mathrm{~km}$ of temperatures (left column) and densities (right column) at 06:00 UT on days 11, 12, and 13. Data are plotted with stars, with their error bars, while the simulations with varying coefficients are plotted with solid lines. For information, we have also plotted in blue the neutral temperature as used in the simulation, which resulted from the analysis of CHAMP data (Figure $2 \mathrm{~d}$ ). On the temperature panel, electrons are in green and ions in red. On the density panel, the electrons are still in green, the atomic ions are plotted in red, while the molecular ions are plotted in magenta (solid lines). We have also added the structure derived from the analysis with the method developed by Blelly et al. (2010) with dashed lines. Moreover, we have added the electron density profile obtained through the simulation with fixed coefficients in black solid line.

Day 11 (top row) has been used to calibrate NRLMSISE-00 atmosphere model, and not surprisingly, we nicely reproduce the vertical structure of the ionosphere. Besides this, the estimation of the neutral temperature from CHAMP data, which leads to a decrease of $70 \mathrm{~K}$ of NRLMSISE-00 exospheric temperature, is correct as the ion temperature profile is well reproduced. Some differences can be seen on the electron temperature profile in $F_{1}$ region which are discussed in section 5.2. These differences do not affect the electron density profile, which is well reproduced by the two simulations (both simulations are using the same coefficients at this time).

On day 12 (middle row), the profiles are just after the perturbation which occurred at 02:00 UT. On temperature panel, the ion and electron temperatures perfectly match the measurement with a neutral temperature which is rather well estimated. Concerning the density panel, we remarkably reproduce the $F_{1}$ region, whatever the correction coefficient we used on the molecular neutrals. The analysis of EISCAT data (Blelly et al., 2010) gives an estimate of the altitude of transition between molecular ions and atomic ions of about $220 \mathrm{~km}$, while IPIM simulation gives $245 \mathrm{~km}$ and IPIM-fix simulation gives $230 \mathrm{~km}$, but IPIM simulation gives better results concerning the electron density profile than IPIM-fix, especially in the $F_{2}$ region.

On day 13 (bottom row), correction coefficients are almost identical in both simulations. Once again, the simulation perfectly matches the data; in particular, the temperature profiles give evidence of the correct estimate of the neutral temperature from CHAMP data. The transition altitude is estimated to be around $195 \mathrm{~km}$, close to the simulation which gives $205 \mathrm{~km}$. Besides this, $F_{1}$ and $F_{2}$ regions are very well reproduced with very similar peak density, resulting in a broadened $F$ region.

Finally, we also compared the temporal structure from the simulations with the one derived from the ionosondes. Thus, we extracted the maximum density in $E$ and $F$ regions from the simulations which were then converted in critical frequencies and compared to $f_{o} E$ and $f_{o} F_{2}$ obtained at Troms $\emptyset$ and Sodankylä. This operation was also done with EISCAT-UHF data, and in order to compare the $F_{2}$ altitude peak, we also extracted from both simulations and radar data the altitude of the peak which is referenced $h_{m} F_{2}$.

The comparison between $f_{o} E$ retrieved at both positions as seen in Figures $5 c$ and 5 e is satisfactory for IPIM-fix simulation (black lines) and IPIM simulation (red lines). These good comparisons confirm the validity of optimization of the correction coefficients on the atmosphere, since $E$ region properties are essentially governed by the underlying atmosphere. As mentioned before, the only clear differences appear when the auroral pre- 


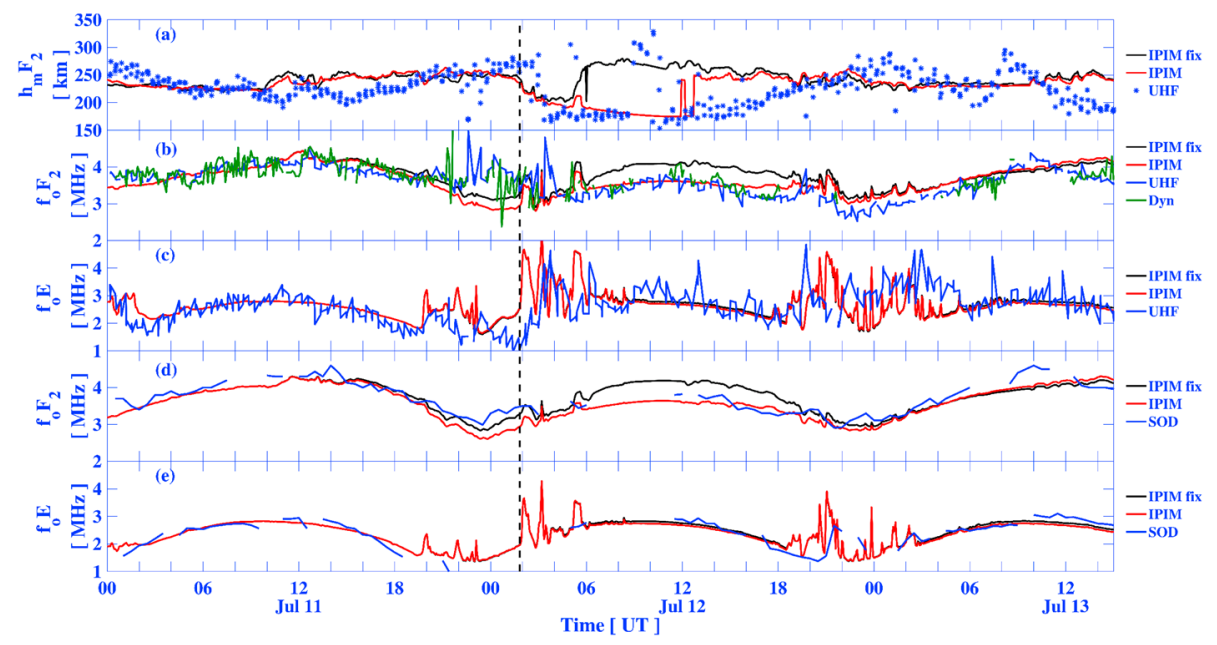

Figure 5. Temporal evolution of $h_{m} F_{2}(\mathrm{a}), f_{o} F_{2}(\mathrm{~b})$, and $f_{o} E$ (c) at Tromsø and $f_{o} F_{2}$ (d) and $f_{o} E$ (e) at Sodankylä locations. On panels (a) to (c), data are obtained from EISCAT (blue line), from Troms $\varnothing$ dynasonde for $f_{o} F_{2}$ only (green) and on panels (d) and (e) from Sodankylä ionosonde (blue line). Simulation results are plotted in red (IPIM) and in black (IPIM-fix). Dynasonde measurements have been used to correct the density from EISCAT by changing the magic factor in GUISDAP analysis. The black dashed vertical line is the same as in Figure 1.

cipitation is the more intense. This precipitation is observed in the same time period for the observations and the simulations, but the patterns differ in the details. These differences can be explained by the relatively poor description of precipitation obtained from the adapted Hardy's model (presented in section 3.2 and Appendix A), since the latter is not parametrized by real data. This can explain possible discrepancies in position, average energy, or particles flux of precipitation between model and observation.

The $f_{o} F_{2}$ comparison is also very satisfactory between observation and both types of simulation on days 11 and 13, although again badly constrained precipitation pattern induces discrepancies especially during the night between days 11 and 12 at Tromsø. On the contrary, IPIM-fix simulation (black lines) and IPIM simulation (red lines) largely differ on day 12 as seen in Figure 5b for Tromsø and Figure 5d for Sodankylä. Indeed, the atmospheric composition perturbation is absolutely essential to follow the $F$ region depletion seen on day 12 just after 02:00 UT at both locations. Finally, despite a very good agreement between observation and simulation with atmospheric composition perturbation, the already mentioned structures observed before noon on days 12 and 13 at EISCAT are clearly visible on $f_{o} F_{2}$ only on day 13 at Troms $\varnothing$ and Sodankylä and are not reproduced by the simulation. This will be discussed in section 5 .

Finally, comparing $h_{m} F_{2}$ retrieved from the EISCAT Tromsø radar and the simulations (see Figure 5a), it is clear that $f_{o} F_{2}$ is not only reduced but also switched to $f_{o} F_{1}$ during day 12 , since $h_{m} F_{2}$ decreases from $250 \mathrm{~km}$ altitude at the end of day 11 to less than $180 \mathrm{~km}$ during day 12. This feature is again evident in the Tromsø observation and in the simulation with varying coefficients, while in the simulation with fixed coefficients, $h_{m} F_{2}$ does not vary much in altitude throughout the event from days 11 to 13. It is important to note that $h_{m} F_{2}$ retrieved from observation and simulation do not match as fairly as $f_{o} F_{2}$ especially during days 11 and 13 . This can be explained by the fact that if the peak density of the $F_{2}$ region is broadened, the determination of the maximum altitude becomes more uncertain (see top and bottom electron density profiles, left column in Figure 4).

\section{Discussion}

\subsection{Mechanisms for $\boldsymbol{F}_{2}$ Layer Depletion}

From the results, we can affirm that the event is not driven by precipitation, as already mentioned by Heelis and Sojka (2011), apart from some localized structures that are discussed in section 5.2. Thus, we do not discuss this aspect in the present section and we focus on the other inputs controlling the simulation. The simulation confirms the key role of the electrodynamics in a two-step mechanism. First, the response of the magnetosphere to the HSS is a sharp increase of the convection when the IMF $B_{z}$ turns southward and the solar wind-magnetosphere energy coupling function Akasofu epsilon starts to increase. This results in a well-documented effect on the ionospheric structure: the convection makes the ion temperature increase through Joule heating which then leads to an increase in the chemical reaction rate between $\mathrm{O}^{+}$and $\mathrm{N}_{2}$ and 
enhances the production of $\mathrm{NO}^{+}$while reducing the concentration of $\mathrm{O}^{+}$(see, e.g., Grandin et al., 2015, and references therein). This is a very efficient process which reduces quite immediately the density in $F_{2}$ region and lasts until the electric field comes back to the background value, typically below $30 \mathrm{mV} / \mathrm{m}$. This is the sharp evolution of the ionospheric structure which is visible on electron density panels in Figure 3 at 02:00 UT on day 12 (black vertical lines on both measurement and simulation). Since there is some particle precipitation causing electron density increase both in the $E$ and lower $F$ regions after 02:00 UT, the change in the $F$ region characteristics is better seen in $h_{m} F_{2}$ in Figure 5 a than in $f_{o} F_{2}$ in Figure $5 \mathrm{~b}$. The altitude changes from $250 \mathrm{~km}$ to about $180 \mathrm{~km}$ just after the electric field increased, as the result of $\mathrm{O}^{+}$ion removal in $F_{2}$ region. This decrease of $f_{o} F_{2}$ is associated with a transition from $F_{2}$ layer to $F_{1}$ layer. Such a perturbation alone would be followed by a recovery phase of a few hours in the case of summer solstice conditions. Indeed, IPIM-fix simulation (black line on 5a) shows that this altitude comes back to $250 \mathrm{~km}$ in about $3 \mathrm{hr}$ after the electric field returns to background value. In such a simulation, we see that the recovery of the $F_{2}$ layer leads to density which is much larger than the one measured by the sounders (ionosonde and incoherent scatter) and thus it cannot explain the decrease observed throughout day 12. Another cause must then be invoked for that, which has been discussed by Heelis and Sojka (2011) and studied by Gardner et al. (2012).

Indeed, in the condition of solar minimum, even a small increase of the PCP is able to induce a significant heating of the neutral atmosphere. Gardner et al. (2012) have modeled the effect of this HSS on the thermosphere, which is embedded in a period of recurrent HSSs. Specifically for 12 July, they showed that the increase of $40 \mathrm{kV}$, which is what occurs at 02:00 UT, is responsible for an increase of 150-200 K of the thermospheric temperature. One important feature from their simulation is that the perturbation propagates rapidly toward low-latitude regions (in a few hours), and it takes a few days to recover to the initial state after the perturbation stops. The analysis of CHAMP data shows that the atmosphere response is instantaneous after the perturbation triggered at 02:00 UT, and the temperature starts increasing to reach a maximum at 07:00 UT, which is $160 \mathrm{~K}$ higher than at the beginning of the period (day 11).

In our simulation, the heating of the atmosphere, and the correlated expansion, is modeled by an increase of the temperature in the thermosphere. Basically, this leads to a change in $[\mathrm{O}] /\left[\mathrm{N}_{2}\right]$ ratio in favor of $\mathrm{N}_{2}$, as the blue line shows in Figure 2e. As we mentioned before, we did not model the dynamics of the atmosphere expansion related to this heating. Though it can be considered as fairly good for $\mathrm{N}_{2}$ and $\mathrm{O}_{2}$, our choice for modeling this expansion by static mechanism (hydrostatic equilibrium with varying neutral temperature profile) does not allow for the true vertical variation of atomic oxygen, which is mainly due to a nonthermal process discussed below.

Proelss (1987) has shown that thermal expansion observed at low latitudes cannot totally explain composition change in the atmosphere. In particular, $[\mathrm{O}] /\left[\mathrm{N}_{2}\right]$ ratio evolves in a way that requires some nonthermal mechanism. Burns et al. (1989) have studied the expansion of the thermosphere with a numerical model and showed that the vertical advection was responsible for the evolution of this ratio in favor of $\mathrm{N}_{2}$ by depleting atomic oxygen. Mikhailov et al. (1997) have estimated that nonthermal effect on atomic oxygen may be of the order of about $30 \%$ of the total change. Most especially, they showed that the equivalent hydrostatic equilibrium for this species leads to a higher scale height which would correspond to a temperature much larger (a few hundreds of Kelvin in their study) than the one derived from $\mathrm{N}_{2}$ profile. Förster et al. (1999) have studied this composition change with numerical simulations and showed that if the hydrostatic equilibrium holds at high altitude, the discrepancy can be important at low altitude (up to $30 \%$ below $120 \mathrm{~km}$ in their study).

Considering the reservoirs at lower altitude for the different species, we can draw a two-step sketch of thermal expansion. First, as a result of atmosphere heating, the neutral species move upward with strong upward velocities (Innis et al., 1999). This transient upward motion allows evolving the hydrostatic equilibrium for the major species $\mathrm{N}_{2}$ and $\mathrm{O}_{2}$, as the temperature increases, without significantly altering the barometric law which can be considered valid for these species with the varying temperature, because they have an infinite reservoir below. Considering the conservation of mass for these species, the strong upwelling velocity will be reduced inversely to the density with decreasing altitude. So the upward velocity at $100 \mathrm{~km}$ would be of the order of 1/10th the one at $115 \mathrm{~km}$ and about 1/50th the one at $130 \mathrm{~km}$, because of a low scale height. Then, the thermospheric expansion would lead to a velocity of a few meters per second in the lower part of the thermosphere $(100 \mathrm{~km})$, not strong enough to affect the density in this region.

However, the minor species like atomic oxygen are more sensitively affected by this transient regime because of a finite reservoir and their higher scale height which in fact corresponds to a depletion in the lower part of 
the atmosphere. Vlasov and Kelley (2010) have studied the effect of eddy diffusion on the atomic oxygen concentration profile in the thermosphere. In particular, the diffusion velocity they used in this region to model the maximum oxygen concentration is a few centimeters per second. This very low velocity is explained by the weakness of $\mathrm{O}_{2}$ photodissociation process which produces atomic oxygen. Indeed, using Kockarts (1994) approach, we found that the characteristic time of production of atomic oxygen at $80 \mathrm{~km}$ is about $4 \mathrm{hr}$ during daytime and $200 \mathrm{hr}$ during nighttime, while at $90 \mathrm{~km}$ it is about 1 day during daytime. Due to the collisions in this region, a vertical expansion velocity of about a few meters per second at $100 \mathrm{~km}$ will be imposed to all minor species and will significantly imbalance their continuity equation. As far as the atomic oxygen is concerned, this expansion will result in a rapid decrease of the concentration in the lower thermosphere because of a low production rate and a straightening at upper altitude as a consequence of the vertical advection.

That is the reason why we have added a variation of the density correction coefficients which follows the perturbation in order to simulate this depletion that would occur in the lower thermosphere. Using these varying coefficients, we were able to reproduce quantitatively the structures observed in the $F_{2}$ region of the ionosphere (curves labeled IPIM) on the day after the perturbation.

The strong transient vertical wind appears in the auroral region where the heating occurs. Then, a horizontal gradient appears which produces a strong horizontal wind blowing from the region of the source toward lower latitude. With respect to Tromsø and Sodankylä, this wind would be observed as coming from the north, as the heating occurs at higher latitude. When projected along the magnetic field, this horizontal component would be seen as an upward wind (about one fifth of the horizontal component due to the dip angle). So whatever, the component of the wind, the effect of the atmosphere on the ionosphere should be observed as an enhancement of the field-aligned ion velocity in the lower part of the ionosphere. After the perturbation starts at 02:00 UT on day 12, we observe such an increase of the field-aligned velocity, which reaches high values below $300 \mathrm{~km}$ (about $100 \mathrm{~m} / \mathrm{s}$, Figure 3).

\subsection{Limits of the Simulation}

There are two main reasons for the difference observed on electron temperature profiles (see Figure 4, top panel). First, in the topside ionosphere, the electron temperature profile is driven by the electron heat flow, which is a major unknown and is roughly estimated for our simulation. Then, in the $F_{1}$ region, electron temperature results from the balance between heating by suprathermal electrons and cooling by ions (Coulomb collisions) and neutrals (elastic collisions and inelastic processes like vibrational or rotational excitation, ... ). Presently for most of these terms, we use the classical expressions, which are based on rather old estimations (Schunk \& Nagy, 1978). Some of these terms have been updated (e.g., Smithtro \& Solomon, 2008, for heating rate and Pavlov, 1998a, 1998b; Pavlov \& Berrington, 1999, for inelastic cooling), but we have not yet included all of them in the model; this could explain at least some of the differences.

As already discussed before, a few specific density features cannot be reproduced in the simulation. Looking at EISCAT density panel in Figure 3, two structures are observed around 23:00 UT (on day 11) and around 02:00 UT (on day 12) corresponding to very localized and higher densities spanning all altitudes from 100 to $300 \mathrm{~km}$. Another density feature is also observed around 10-11 UT (on day 12) above $250 \mathrm{~km}$ altitude. Finally, a last density feature is observed on the form of a very broad $F$ region up to $400 \mathrm{~km}$ altitude, again around 10-12 UT (on day 13), which is also observed by the Sodankylä ionosonde.

The first two structures are occurring when the Akasofu epsilon function increases, for one close to 23:00 UT (on day 11) and for the other close to the convection enhancement following the IMF $B_{z}$ southward turning (black dashed vertical line in Figure 1). Thus, they are clearly associated with wide energy spectra precipitation; the first one is not reproduced by IPIM, while the second one is only poorly reproduced since the structure is more confined in altitude in the simulation. This confirms that the adapted Hardy's model, while generally identifying the correct periods when precipitation occurs, does not model correctly the particle spectra and potential spatial inhomogeneity.

The two features with density broadening above $250 \mathrm{~km}$ altitude before noon on days 12 and 13 are more puzzling, and two possible explanations can be suggested: either soft precipitation or ionosphere upwelling which can be either due to northward convection or southward neutral wind.

In their ionosonde statistical study, Grandin et al. (2015) showed that a short-lived increase of electron density peak occurred around noon during the day following the HSS arrival and was possibly explained by a solar wind pressure pulse triggered by the CIR. The density feature observed at EISCAT around 10-11 UT 
(day 12) is occurring at the same time than the one observed by Grandin et al. (2015) and is concomitant with a steepening of the solar wind speed gradient. Moreover, this feature is also accompanied by higher-energy precipitation causing quasi-simultaneous local $E$ region enhancement and weak ionosphere heating as seen on ion temperature. All these observations show that this explanation is plausible. However, the adapted Hardy's model is again lacking in reproducing correctly such precipitation. This explanation is more unlikely for the broadened $F$ region around 10-11 UT on day 13 with no $E$ region precipitation and no ionosphere heating.

Expansion of the convection cell with northward convection to lower latitudes would allow extraction of ionosphere material from denser midlatitude region and transport toward higher latitudes through antisunward convection in the noon sector. This material would rise due to magnetic field line geometry. This seems unlikely, since looking at EISCAT and SuperDARN electric field data, convection has already largely reduced during these two noon periods on days 12 and 13. Similarly, southward neutral wind would transport plasma upward along magnetic field lines through a mechanism that we already mentioned in the previous section. We lack experimental observation of neutral wind, and so we cannot confirm nor reject the southward neutral wind hypothesis and we cannot even rely on HWM14 model as it suffers from the same limitation than the NRLMSISE-00 model; this is a climatological model not designed to follow dynamical situations even when using the perturbed version of the model. However, a southward neutral wind near noon is relatively inconsistent with usual pattern observed at high latitudes even during perturbed periods (Förster et al., 2008). Finally, such upwelling would contribute to an expansion of the $F$ region causing a local ionosphere cooling which is not observed on EISCAT ion temperature for neither of the two features. It is then difficult to conclude that such an upwelling effect is causing these broadened $F$ regions before noon.

\section{Conclusion and Perspective}

This study was carried out to understand the effect of a HSS event on the high-latitude ionosphere and more specifically the observed decrease of the $f_{o} F_{2}$ frequency during the entire day following the impact (Grandin et al., 2015). For that, we have selected one HSS starting 11 July 2008, in summertime, as a large data set was available: SuperDARN for global plasma convection, EISCAT IS radars and Troms $\varnothing$ and Sodankylä ionosondes for ionosphere, and CHAMP for atmosphere. This event was characterized by a typical $f_{o} F_{2}$ frequency behavior (reduction at all local times on the day following the arrival of the HSS), and we modeled, with the IPIM model (Marchaudon \& Blelly, 2015), the dynamics of the ionosphere at Tromsø and Sodankylä using inputs derived from the data. Troms $\varnothing$ was considered as the reference test, since full profiles measured by the EISCAT-UHF radar were available and Sodankylä as the blind test.

An initial adjustment of the atmosphere was required for this period which corresponds to an unusually low solar activity $\left(F_{10.7}<70\right)$. For that, we used EISCAT-UHF and CHAMP data to calibrate the IPIM model and provide correction coefficients to the NRLMSISE-00 atmosphere model.

We obtained results from the simulations which nicely match the measurements made by IS radar and ionosondes at both locations, and we mainly showed that the decrease of $f_{o} F_{2}$ is associated with a transition from $F_{2}$ layer to $F_{1}$ layer resulting from a decrease of neutral atomic oxygen concentration.

SuperDARN and CHAMP provided a good estimation of the temporal evolution of, respectively, the convection and the atmosphere during the event and allowed discriminating the different steps of the ionospheric response to this HSS. In particular, it was shown that electrodynamics can explain the short-term behavior of the ionosphere on the scale of a few hours, but the long-term behavior on the scale of a few days results from the perturbation induced on the atmosphere. Both are associated with the enhancement in plasma convection in the polar ionosphere during the solar wind HSS event. It is first responsible for a sharp increase of the ion temperature by Joule heating, which favors the chemistry between $\mathrm{O}^{+}$and $\mathrm{N}_{2}$ producing $\mathrm{NO}^{+}$and leads to an immediate reduction of the $F_{2}$ layer. Then, the ion drag on the neutral atmosphere is responsible for heating and expansion of the polar thermosphere which propagates on a very short period of time from high to low latitudes. This expansion affects the atomic oxygen through a nonthermal upward flow which results in a decrease of its concentration and amplifies the well-known decrease of $[\mathrm{O}] /\left[\mathrm{N}_{2}\right]$ ratio due to the thermal expansion. This thermosphere alteration lasts at least 1 day and explains the long-term extinction of $F_{2}$ layer.

In the future, this study should be extended to better characterize the response of the ionosphere to HSS and we foresee two aspects that should be covered. 
First, the model has been calibrated using EISCAT-UHF and CHAMP data and the simulations at Tromsø and Sodankylä locations correspond to a perturbation occurring in the morning MLT sector. It could be interesting to extend the simulation with this parametrization to the evening sector, and we intend to model PFISR observations made during the World Day campaign which covers this event. Then, this event occurs in summertime and we know that the response is different during other seasons. So we plan to study HSS events observed in spring or fall and winter time. However, we need to get a data set as complete as the one we used in this study, which may prove difficult, so we will start by modeling the impact of this HSS in southern hemisphere, at Tromsø conjugate location.

Finally, the differences between observed and modeled electron temperatures question the thermal balance we solve in the model. However, the fact that we are in an unusual low solar activity period may also play a role in this difference. Thus, a specific study of the balance during this event should be undertaken.

\section{Appendix A: Definition of $K_{p}^{\text {eq }}$}

As described on the CCMC web site, Ovation Prime is a statistical model binned by MLT and latitude, each cell being parametrized by solar wind inputs (density, velocity, and magnetic field) independently from the others. Thus, the model provides a noisy energy flux map of the auroral electron precipitation which is not directly useable. So we derived a process to take advantage of Ovation statistics in Hardy's model which gives the particle flux and energy flux which are the parameters required by IPIM. The first operation consists in smoothing the precipitation patterns by spherical harmonics filtering. Then, from every smoothed analytical pattern, we extract the latitude $\lambda^{\max }$ and amplitude $\phi_{E}^{\max }$ of the maximum of the energy flux. A posteriori, we checked that $\phi_{E}^{\max }$ can be considered as a proxy of the total precipitation energy and we used it in our parametrization.

Epstein functions in Hardy's model are such that we can easily extract the latitude of the maximum of energy flux for every $K_{p}$-dependent map. Doing that, we were able to build a reference function $K_{p}\left(\lambda^{\max }\right)$ which provides the $K_{p}$ to use in Hardy's model for a given $\lambda^{\text {max }}$. This function was then used for adjusting Ovation prime to Hardy's model using $\lambda^{\text {max }}$. Left panel of Figure A1 shows the derived $K_{p}^{\text {eq }}$ for Hardy's model as a function of $\phi_{E}^{\max }$ extracted from Ovation Prime. There is a nice dependency between both parameters (blue dots) which could be fitted by a double hyperbolic tangent function (red line).

Finally, the IPIM model was modified to get as an input, the temporal evolution of $\phi_{E}^{\max }$ obtained from the analysis of Ovation Prime data, which was used to parameterized Hardy's model. Figure 2a shows the comparison between $K_{p}$ and $K_{p}^{\mathrm{eq}}$. Due to the $3-\mathrm{hr}$ resolution, $K_{p}$ is not able to follow the perturbation, while $K_{p}^{\mathrm{eq}}$
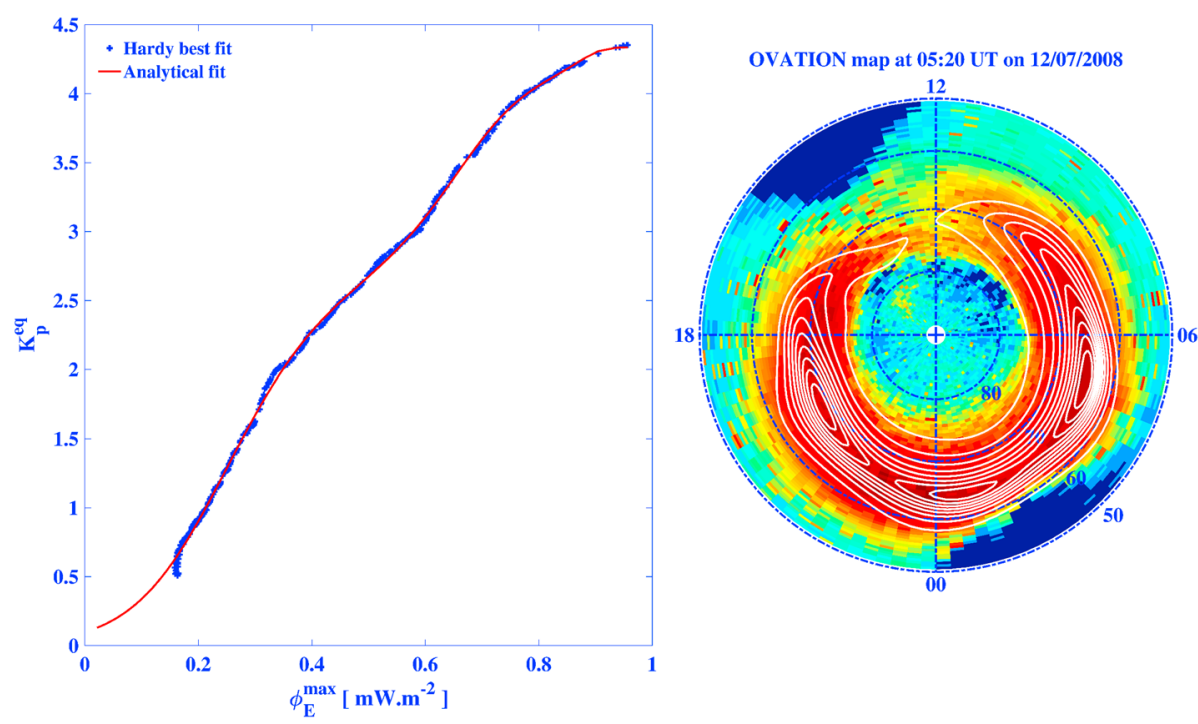

Figure A1. Left panel: $K_{p}^{\mathrm{eq}}$ used as entry to Hardy's model as a function of the maximum of energy flux $\phi_{E}^{\text {max }}$ derived from Ovation Prime. Right panel: polar view of electron precipitation energy flux patterns from Ovation Prime (color plot) and corresponding Hardy's model (white contours) at the maximum of the perturbation at 05:20 UT on 12 July 2008. 
Acknowledgments

An online version of IPIM is available on transplanet web interface (http:// transplanet.irap.omp.eu/), and the simulations made for this study are available at the following link http://transplanet.irap.omp.eu/ published.html. IPIM model is a property of CNRS. EISCAT data are available from the MADRIGAL database (https://www.eiscat.se/madrigal). SuperDARN convection maps are available from Virginia Tech (http://vt.superdarn.org/); the French SuperDARN team is supported by PNST, INSU/CNRS and Institut Paul Emile Victor (IPEV). We are grateful to Eelco Doornbos for providing CHAMP accelerometer data (http:// thermosphere.tudelft.nl/acceldrag/ data.php). Ovation Prime simulation results have been provided by the Community Coordinated Modeling Center at Goddard Space Flight Center through their public Runs on Request system (https://ccmc.gsfc.nasa.gov). The Ovation Prime Model was developed by P. Newell at John Hopkins University Applied Physics Laboratory. The OMNI data were obtained from the GSFC/SPDF OMNIWeb interface at https://ccmc.gsfc.nasa.gov. This work is supported by the Programme National Soleil Terre (PNST) from Institut des Sciences de I'Univers of Centre National de la Recherche Scientifique (INSU/CNRS) cofunded by CNES and by the Academy of Finland project 285474 M. G. is supported by the Academy of Finland (grant 312351). This work was granted access to the HPC resources of CALMIP supercomputing center under the allocation 2017-P1520. is clearly controlled by the solar wind (see, e.g., Akasofu function in Figure 1c) and phased with the perturbation on the electrodynamics at Tromsø (Figure $2 b$ ). Moreover, we see that the maximum reached by $K_{p}^{\text {eq }}$ is consistent with maximum value of $K_{p}$. Right panel of Figure A1 gives the comparison between Ovation Prime and Hardy's model at the maximum of the perturbation which occurred on 12 July at 05:20 UT. The color patterns are the data from Ovation Prime, while the white contours are the ones we get from Hardy's model. We can see how noisy Ovation Prime data are, and even though there is not a perfect matching between both models, we get the general pattern.

\section{Acronyms}

CCMC Community Coordinated Modeling Center

CHAMP CHAllenging Minisatellite Payload

CIR Corotating Interaction Region

CME Coronal Mass Ejection

EISCAT European Incoherent SCATter Scientific Association

EISCAT-UHF EISCAT tristatic UHF radar

ESR EISCAT Svalbard Radar

FISM Flare Irradiance Spectral Model

GUISDAP Grand Unified Incoherent Scatter Design and Analysis Program

GUVI Global UltraViolet Imager

HSS High-Speed Stream

HWM07 Horizontal Wind Model (2007 version)

HWM14 Horizontal Wind Model (2014 version)

IMF Interplanetary Magnetic Field

IPIM IRAP Plasmasphere lonosphere Model

IS Incoherent Scatter

MLT Magnetic Local Time

NH Northern Hemisphere

NRLMSISE-00Naval Research Laboratory Mass Spectrometer Incoherent Scatter radar

OMNI Operating Missions as a Node on the Internet

PCP Polar Cap Potential

PFISR Poker Flat Incoherent Scatter Radar

SuperDARN Super Dual Auroral Radar Network

TIMED Thermosphere lonosphere Mesosphere Energetics and Dynamics mission

TRANSCAR TRANSport au CARré

UARS Upper Atmosphere Research Satellite

UT Universal Time

\section{References}

Akasofu, S.-I. (1979). Interplanetary energy flux associated with magnetospheric substorms. Planetary and Space Science, 27, $425-431$. https://doi.org/10.1016/0032-0633(79)90119-3

Bartels, J. (1949). The standardized index, Ks, and the planetary index, Kp. IATME Bulletin, 12b, 97

Blelly, P.-L., Alcaydé, D., \& van Eyken, A. P. (2010). A new analysis method for determining polar ionosphere and upper atmosphere characteristics from ESR data: Illustration with IPY period. Journal of Geophysical Research, 115, A09322. https://doi.org/10.1029/2009JA014876

Blelly, P.-L., Lathuillère, C., Emery, B., Lilensten, J., Fontanari, J., \& Alcaydé, D. (2005). An extended TRANSCAR model including ionospheric convection: Simulation of EISCAT observations using inputs from AMIE. Annales de Geophysique, 23, $419-431$. https://doi.org/10.5194/angeo-23-419-2005

Blelly, P.-L., Robineau, A., Lilensten, J., \& Lummerzheim, D. (1996). 8-moment fluid models of the terrestrial high-latitude ionosphere between 100 and 3000 km. In R. W. Schunk (Ed.), STEP Handbook on lonospheric Models (pp. 53-72). Logan, UT: Utah State Univerisity.

Blelly, P.-L., \& Schunk, R. W. (1993). A comparative study of the time-dependent standard 8-, 13- and 16-moment transport formulations of the polar wind. Annales de Geophysique, 11, 443-469.

Burns, A. G., Killeen, T. L., Crowley, G., Emery, B. A., \& Roble, R. G. (1989). On the mechanisms responsible for high-latitude thermospheric composition variations during the recovery phase of a geomagnetic storm. Journal of Geophysical Research, 94, 16,961-16,968. https://doi.org/10.1029/JA094iA12p16961

Chamberlin, P. C., Woods, T. N., \& Eparvier, F. G. (2007). Flare irradiance spectral model (FISM): Daily component algorithms and results. Space Weather, 5, S07005. https://doi.org/10.1029/2007SW000316

Crowley, G., Reynolds, A., Thayer, J. P., Lei, J., Paxton, L. J., Christensen, A. B., et al. (2008). Periodic modulations in thermospheric composition by solar wind high speed streams. Geophysical Research Letters, 35, L21106. https://doi.org/10.1029/2008GL035745

Denton, M. H., Ulich, T., \& Turunen, E. (2009). Modification of midlatitude ionospheric parameters in the F2 layer by persistent high-speed solar wind streams. Space Weather, 7, S04006. https://doi.org/10.1029/2008SW000443 
Drob, D. P., Emmert, J. T., Crowley, G., Picone, J. M., Shepherd, G. G., Skinner, W., et al. (2008). An empirical model of the Earth's horizontal wind fields: HWM07. Journal of Geophysical Research, 113, A12304. https://doi.org/10.1029/2008JA013668

Emmert, J. T., Drob, D. P., Shepherd, G. G., Hernandez, G., Jarvis, M. J., Meriwether, J. W., et al. (2008). DWM07 Global empirical model of upper thermospheric storm-induced disturbance winds. Journal of Geophysical Research, 113, A11319. https://doi.org/10.1029/2008JA013541

Förster, M., Namgaladze, A. A., \& Yurik, R. Y. (1999). Thermospheric composition changes deduced from geomagnetic storm modeling Geophysical Research Letters, 26, 2625-2628. https://doi.org/10.1029/1999GL900514

Förster, M., Rentz, S., Köhler, W., Liu, H., \& Haaland, S. E. (2008). IMF Dependence of high-latitude thermospheric wind pattern derived from CHAMP cross-track measurements. Annales Geophysicae, 26, 1581-1595. https://doi.org/10.5194/angeo-26-1581-2008

Gardner, L., Sojka, J. J., Schunk, R. W., \& Heelis, R. (2012). Changes in thermospheric temperature induced by high-speed solar wind streams. Journal of Geophysical Research, 117, A12303. https://doi.org/10.1029/2012JA017892

Gosling, J. T. (1996). Corotating and transient solar wind flows in three dimensions. Annual Review of Astronomy and Astrophysics, $34,35-74$. https://doi.org/10.1146/annurev.astro.34.1.35

Grandin, M., Aikio, A. T., Kozlovsky, A., Ulich, T., \& Raita, T. (2015). Effects of solar wind high-speed streams on the high-latitude ionosphere: Superposed epoch study. Journal of Geophysical Research: Space Physics, 120, 10,669-10,687. https://doi.org/10.1002/2015JA021785

Grandin, M., Aikio, A. T., Kozlovsky, A., Ulich, T., \& Raita, T. (2017). Cosmic radio noise absorption in the high-latitude ionosphere during solar wind high-speed streams. Journal of Geophysical Research: Space Physics, 122, 5203-5223. https://doi.org/10.1002/2017JA023923

Greenwald, R. A., Baker, K. B., Dudeney, J. R., Pinnock, M., Jones, T. B., Thomas, E. C., et al. (1995). Darn/Superdarn: A global view of the dynamics of high-latitude convection. Space Science Reviews, 71, 761-796. https://doi.org/10.1007/BF00751350

Hardy, D. A., Gussenhoven, M. S., Raistrick, R., \& McNeil, W. J. (1987). Statistical and functional representations of the pattern of auroral energy flux, number flux, and conductivity. Journal of Geophysical Research, 92, 12,275-12,294. https://doi.org/10.1029/JA092iA11p12275

Heelis, R. A., \& Sojka, J. J. (2011). Response of the topside ionosphere to high-speed solar wind streams. Journal of Geophysical Research, 116 , A11314. https://doi.org/10.1029/2011JA016739

Innis, J. L., Greet, P. A., Murphy, D. J., Conde, M. G., \& Dyson, P. L. (1999). A large vertical wind in the thermosphere at the auroral oval/polar cap boundary seen simultaneously from Mawson and Davis, Antarctica. Journal of Atmospheric and Solar-Terrestrial Physics, 61, 1047-1058. https://doi.org/10.1016/S1364-6826(99)00060-7

Kockarts, G. (1994). Penetration of solar radiation in the Schumann-Runge bands of molecular oxygen: A robust approximation. Annales Geophysicae, 12, 1207-1217.

Marchaudon, A., \& Blelly, P.-L. (2015). A new interhemispheric 16-moment model of the plasmasphere-ionosphere system: IPIM. Journal of Geophysical Research: Space Physics, 120, 5728-5745. https://doi.org/10.1002/2015JA021193

Meier, R. R., Picone, J. M., Drob, D., Bishop, J., Emmert, J. T., Lean, J. L., et al. (2015). Remote sensing of Earth's limb by TIMED/GUVI: Retrieval of thermospheric composition and temperature. Earth and Space Science, 2, 1-37. https://doi.org/10.1002/2014EA000035

Mikhailov, A. V., Förster, M., \& Skoblin, M. G. (1997). An estimate of the non-barometric effect in the [O] height distribution at low latitudes during magnetically disturbed periods. Journal of Atmospheric and Solar-Terrestrial Physics, 59, $1209-1215$. https://doi.org/10.1016/S1364-6826(96)00089-2

Newell, P. T., Sotirelis, T., \& Wing, S. (2009). Diffuse, monoenergetic, and broadband aurora: The global precipitation budget. Journal of Geophysical Research, 114, A09207. https://doi.org/10.1029/2009JA014326

Pavlov, A. V. (1998a). New electron energy transfer rates for vibrational excitation of $\mathrm{N}_{2}$. Annales Geophysicae, 16, $176-182$. https://doi.org/10.1007/s00585-998-0176-9

Pavlov, A. V. (1998b). New electron energy transfer and cooling rates by excitation of $\mathrm{O}_{2}$. Annales Geophysicae, 16, 1007-1013. https://doi.org/10.1007/s00585-998-1007-8

Pavlov, A. V., \& Berrington, K. A. (1999). Cooling rate of thermal electrons by electron impact excitation of fine structure levels of atomic oxygen. Annales Geophysicae, 17, 919-924. https://doi.org/10.1007/s00585-999-0919-2

Picone, J. M., Hedin, A. E., Drob, D. P., \& Aikin, A. C. (2002). NRLMSISE-00 empirical model of the atmosphere: Statistical comparisons and scientific issues. Journal of Geophysical Research, 107(A12), 1468. https://doi.org/10.1029/2002JA009430

Proelss, G. W. (1987). Storm-induced changes in the thermospheric composition at middle latitudes. Planetary and Space Science, 35, 807-811. https://doi.org/10.1016/0032-0633(87)90041-9

Ruohoniemi, J. M., \& Baker, K. B. (1998). Large-scale imaging of high-latitude convection with super dual auroral radar network HF radar observations. Journal of Geophysical Research, 103, 20,797-20,811. https://doi.org/10.1029/98JA01288

Schunk, R. W., \& Nagy, A. F. (1978). Electron temperatures in the $F$ region of the ionosphere-Theory and observations. Reviews of Geophysics and Space Physics, 16, 355-399. https://doi.org/10.1029/RG016i003p00355

Smithtro, C. G., \& Solomon, S. C. (2008). An improved parameterization of thermal electron heating by photoelectrons, with application to an x17 flare. Journal of Geophysical Research, 113, A08307. https://doi.org/10.1029/2008JA013077

Sojka, J. J., McPherron, R. L., van Eyken, A. P., Nicolls, M. J., Heinselman, C. J., \& Kelly, J. D. (2009). Observations of ionospheric heating during the passage of solar coronal hole fast streams. Geophysical Research Letters, 36, L19105. https://doi.org/10.1029/2009GL039064

Sotirelis, T., \& Newell, P. T. (2000). Boundary-oriented electron precipitation model. Journal of Geophysical Research, $105,18$. https://doi.org/10.1029/1999JA000269

Strickland, D. J., Evans, J. S., \& Paxton, L. J. (1995). Satellite remote sensing of thermospheric O/ $\mathrm{N}_{2}$ and solar EUV. 1: Theory. Journal of Geophysical Research, 100, 12,217-12,226. https://doi.org/10.1029/95JA00574

Sugiura, M. (1964). Hourly Values of Equatorial Dst for the IGY, Ann. Int. Geophys. Year, 35, 9. Oxford: Pergamon Press.

Thayer, J. P., Lei, J., Forbes, J. M., Sutton, E. K., \& Nerem, R. S. (2008). Thermospheric density oscillations due to periodic solar wind high-speed streams. Journal of Geophysical Research, 113, A06307. https://doi.org/10.1029/2008JA013190

Tsurutani, B. T., Gonzalez, W. D., Gonzalez, A. L. C., Guarnieri, F. L., Gopalswamy, N., Grande, M., et al. (2006). Corotating solar wind streams and recurrent geomagnetic activity: A review. Journal of Geophysical Research, 111, A07S01. https://doi.org/10.1029/2005JA011273

Turner, N. E., Cramer, W. D., Earles, S. K., \& Emery, B. A. (2009). Geoefficiency and energy partitioning in CIR-driven and CME-driven storms. Journal of Atmospheric and Solar-Terrestrial Physics, 71, 1023-1031. https://doi.org/10.1016/j.jastp.2009.02.005

Vlasov, M. N., \& Kelley, M. C. (2010). Estimates of eddy turbulence consistent with seasonal variations of atomic oxygen and its possible role in the seasonal cycle of mesopause temperature. Annales Geophysicae, 28, 2103-2110. https://doi.org/10.5194/angeo-28-2103-2010 